\title{
FORMA DE ATUAÇÃO E PERCEPÇÃO DOS DIRIGENTES DE EMPRESAS PRESTADORAS DE SERVIÇO FLORESTAL EM DUAS REGIÕES DO ESTADO DE SANTA CATARINA
}

\author{
Dagoberto Stein de Quadros ${ }^{1}$, Jorge Roberto Malinovski ${ }^{2}$ \\ ${ }^{1}$ Eng. Florestal, Dr., Depto. de Engenharia Florestal, FURB, Blumenau, SC, Brasil - dagobert @ furb.br \\ ${ }^{2}$ Eng. Florestal, Dr., Depto. de Ciências Florestais, UFPR, Curitiba, PR, Brasil - malinovski@ufpr.br \\ Recebido para publicação: 15/03/2010 - Aceito para publicação: 08/09/2011
}

\begin{abstract}
Resumo
Este trabalho teve como objetivo caracterizar as prestadoras de serviço florestal a partir de análises das formas de atuação e da percepção dos dirigentes dessas empresas. Foram amostradas 46 empresas que executam atividades de silvicultura, colheita de madeira e transporte florestal em diferentes graus de mecanização. Os resultados obtidos caracterizaram as atividades desenvolvidas pelas prestadoras de serviço, as formas de contratação, os contratantes e a estrutura operacional. Analisou-se a percepção dos dirigentes a respeito dos principais parâmetros econômicos de suas empresas. O estudo concluiu que as prestadoras de serviço são subordinadas tecnicamente às empresas contratantes. Os principais problemas percebidos pelos dirigentes estão associados às questões técnicas e não às econômicas. A maioria dos dirigentes não possui escolaridade suficiente para administrar economicamente as prestadoras de serviço e não faz essas análises. As prestadoras de serviço localizadas na região do Vale do Itajaí possuem intensa utilização de mão de obra na produção, e as localizadas no Planalto Serrano possuem alto grau de mecanização.

Palavras-chave: Prestadoras de serviço florestal; formas de contratação; estrutura operacional.
\end{abstract}

\begin{abstract}
Forms of performance and perception of the controllers of rendering companies of forest service in two regions of the state of Santa Catarina. This work aims at characterizing forest service rendering the forms of performance and perception of the controllers. Forty six companies were sampled, which carry out forestry services, wood extraction, and forest transport at different mechanization levels. The obtained results characterize the activities developed by the service renderers, the hiring manners, the contractors, and the operational structure. The management perception with respect to the main economic parameters of the companies was analyzed. The study has concluded that the service renderers are technically subordinated to the contracting companies. The main problems noted by the management are associated to technical, but not economic questions. Most of the managers are not sufficiently educated for running their companies economically and do not perform such analyses. While companies localized in the 'Vale do Itajai' employ intense labor force at production and those localized in the 'Planalto Serrano' region are highly mechanize.

Keywords: Forest service renderer; hiring manners; operational structure.
\end{abstract}

\section{INTRODUÇÃO}

As empresas do setor florestal brasileiro executam os serviços relacionados às áreas de reflorestamento, em grande parte, através de empresas prestadoras de serviço florestal que, de certo modo, são uma das bases de sustentação dos segmentos industriais que utilizam a madeira oriunda de reflorestamentos no seu processo produtivo.

A história nos mostra que as atividades florestais no Brasil geralmente eram realizadas por trabalhadores contratados através das chamadas "empreitadas". No entanto, o processo de terceirização se iniciou de forma mais profissional no final da década de 80 e início dos anos 90 . Ele se deu por iniciativa das próprias empresas florestais da época, que, através do financiamento de máquinas aos seus funcionários, incentivaram-nos a criar as primeiras empresas prestadoras de serviço florestal. 
Esse processo se baseou na terceirização, que se caracteriza pela transferência para outras empresas, mediante contrato, de atividades não essenciais da empresa (LACOMBE; HEILBORN, 2003). Um dos objetivos da terceirização é a redução de custos de produção com manutenção da qualidade e garantia de abastecimento (MALINOVSKI, 2004).

A evolução das empresas prestadoras de serviço nos aspectos administrativo, técnico, legais e sociais foi expressiva nos últimos anos, no entanto, deve-se, continuamente, buscar um aprimoramento na gestão empresarial, para atingir melhores patamares de administração empresarial por parte dos prestadores de serviço (SALAMUNI, 2004).

Fernandes (2002) defende que, para se consolidar a terceirização no setor florestal brasileiro, é necessário promover o desenvolvimento empresarial, tanto nos aspectos técnicos como administrativos. Binda (2002) evidencia ainda que "a contratação de serviços de terceiros na área florestal, via de regra, não pode estar calçada na simples análise do menor preço ofertado, pois geralmente o menor preço está associado a uma infinidade de problemas". Sant'Anna Jr. e Lazaretti (2006) afirmam que esforços estão sendo direcionados nas contratações de serviços permanentes, no fortalecimento das empresas e na melhoria das habilidades e especialidades.

No setor de prestação de serviço florestal inexiste a cultura empresarial focada em resultados econômicos e em qualidade contínua. Fernandes (2002) enfatiza a necessidade de aprimoramento dos sistemas de controles de atividades operacionais e dos custos das atividades.

Os principais temas de discussão a respeito de terceirização no setor de base florestal se referem, entre outros, ao prazo dos contratos, à forma de reajuste de preços, à definição de capacitação empresarial dos dirigentes das empresas prestadoras de serviço e, sobretudo, à definição de um sistema de avaliação de resultados financeiros e operacionais (MALINOVSKI, 2004).

A partir do histórico acima, assim como da conjuntura atual que envolve a temática, este trabalho teve como problema de pesquisa o seguinte questionamento: "Quais são as características das empresas prestadoras de serviço florestal que atuam em duas distintas regiões do estado de Santa Catarina?

Diante do problema acima evidenciado, este trabalho teve como principal objetivo a caracterização das empresas prestadoras de serviço florestal em termos da sua forma de atuação, buscando-se identificar o capital investido, os turnos de trabalho, o contratante, a forma de contratação, o número de funcionários administrativos e de produção e seus salários e a escolaridade dos dirigentes. Também objetivou-se definir a percepção dos parâmetros econômicos dessas empresas, por parte de seus dirigentes, especificamente em termos de necessidade de treinamento, principais problemas, vantagens e desvantagens da atividade, forma de aquisição de máquinas e implementos, análise de custos e de rentabilidade, assim como os encargos sociais e as despesas governamentais associados à atividade.

A caracterização da forma de atuação estruturada neste estudo e a definição da percepção dos parâmetros econômicos evidenciados pelos dirigentes dessas empresas prestadoras de serviço florestal permitem distinguir e conhecer as empresas que atuam em distintas regiões, sendo esta a hipótese principal do presente estudo.

\section{MATERIAIS E MÉTODOS}

\section{Material}

O estudo foi realizado em duas regiões do estado de Santa Catarina (Figura 1). A Região I localiza-se no Vale do Itajaí - SC e foi composta pelos municípios de Apiúna, Ascurra, Blumenau, Gaspar, Ibirama, Indaial e Timbó. Essa região possui a sua economia baseada na indústria têxtil e de alimentos, havendo poucas empresas de base florestal, de modo que a atividade florestal não é a principal atividade da economia regional. O relevo que predomina é o montanhoso, com alta incidência de ravinas, e a vegetação original constitui-se de Floresta Ombrófila Densa. Existe na região reflorestamentos dos gêneros eucalipto e pinus, mas predominam os do gênero eucalipto.

A Região II localiza-se no Planalto Serrano - SC e foi composta pelos municípios de Correia Pinto, Lages, Otacílio Costa, Palmeira, Ponte Alta, Ponte Alta do Norte, Santa Cecília e São Cristóvão do Sul. Essa região possui a sua economia baseada na indústria de base florestal, existindo diversas empresas produtoras de papel, celulose e painéis, além de serrarias. Saliente-se que a atividade de reflorestamento é a sustentação da economia regional e que predominam os reflorestamentos do gênero Pinus. O relevo dominante é suave ondulado, e a vegetação original constitui-se de Floresta Ombrófila Mista. 


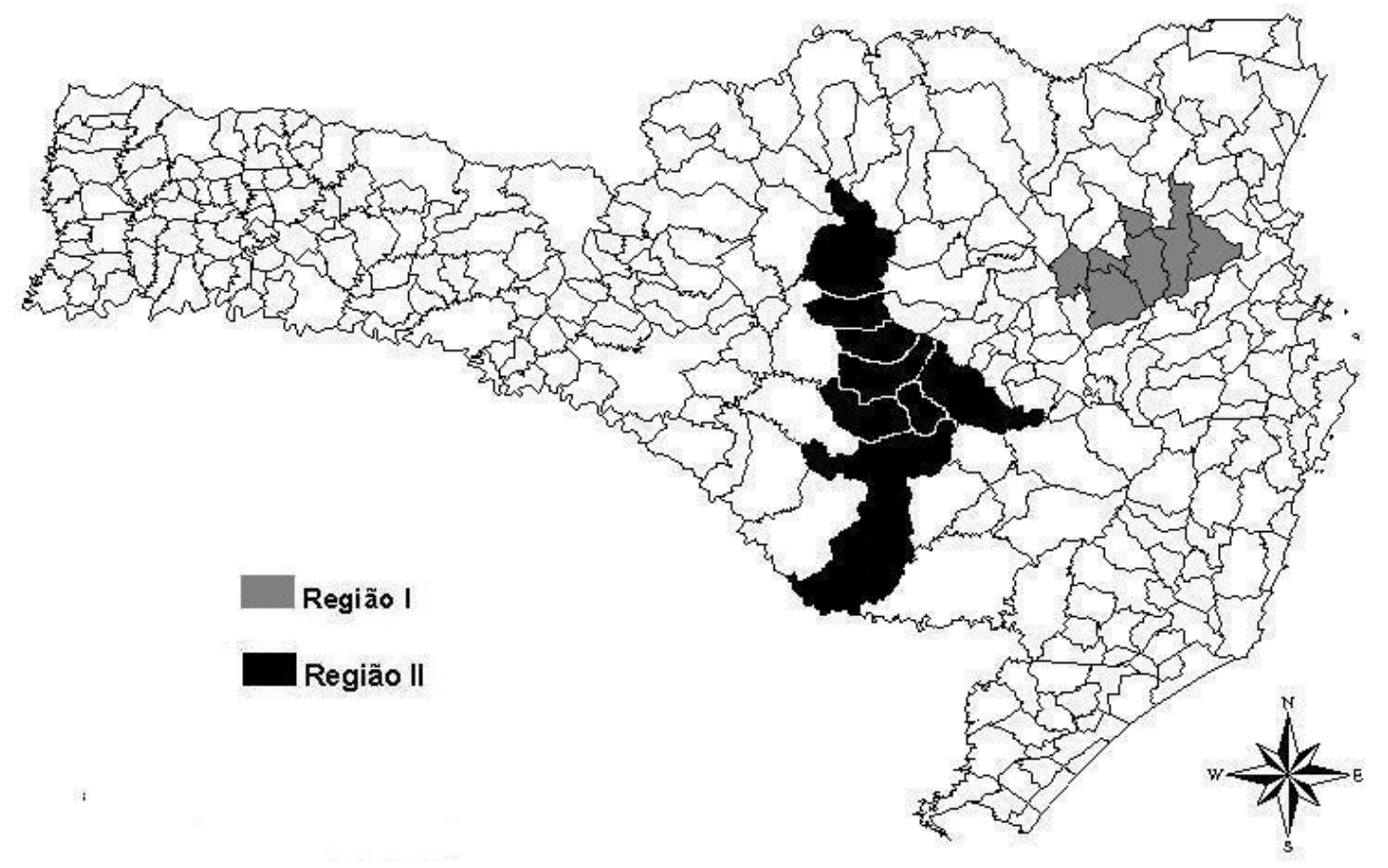

Figura 1. Localização das regiões de estudo no estado de Santa Catarina. Figure 1. Localization of the study regions of the state of Santa Catarina. Fonte: Florianópolis. Governo do estado de Santa Catarina (2008).

Justifica-se a escolha dessas duas regiões por serem distintas e representarem a atividade de reflorestamento no estado de Santa Catarina. A primeira região, Vale do Itajaí, representa as regiões em que o reflorestamento não é a principal atividade econômica regional. A segunda, Planalto Serrano, representa as regiões em que o reflorestamento, de certa forma, confere sustentação econômica à região.

A amostra foi obtida através de um cadastro das empresas prestadoras de serviço florestal que atuam nas duas regiões do estudo. Esse cadastro foi realizado a partir das empresas que se utilizam de prestadores de serviço para executar as atividades de silvicultura, colheita de madeira e transporte florestal em suas áreas de reflorestamento. Foram cadastradas 142 empresas prestadoras de serviço, das quais 84 não mostraram interesse em participar dessa pesquisa. Das 58 empresas prestadoras de serviço restantes, eliminaram-se 12, pois os dados fornecidos por elas foram inconsistentes. Dessa forma, foram analisadas 46 empresas prestadoras de serviço florestal, que constituíram a amostra do presente estudo. A tabela 1 apresenta esses dados por região.

Tabela 1. Empresas prestadoras de serviço cadastradas, pré-analisadas e pesquisadas.

Table 1. Registered in cadastre, daily analyze and searched rendering companies of service.

\begin{tabular}{lccc}
\hline Localização & Cadastradas & Pré-analisadas & Amostradas \\
\hline Região I & 81 & 32 & 24 \\
Região II & 61 & 26 & 22 \\
\hline Total & 142 & 58 & 46 \\
\hline
\end{tabular}

Estratificou-se a amostra a partir das atividades de silvicultura, colheita de madeira e transporte florestal. Essas atividades assim se caracterizam:

- Silvicultura - empresas que atuam em implantação de reflorestamento, especificamente nas operações de preparo do terreno, plantio e tratos culturais e silviculturais (não se incluíram aqui as empresas de produção de mudas florestais); 
- Colheita de Madeira - empresas que executam atividades de desbaste e/ou corte raso de reflorestamentos;

- Transporte Florestal - empresas que realizam o transporte de madeira na forma de toretes e toras originadas de reflorestamentos.

As empresas prestadoras de serviço também foram classificadas pelo seu grau de mecanização, a partir dos seguintes critérios:

- Manual - empresas que se utilizam serviços manuais, além de máquinas e implementos portáteis;

- Semimecanizado - empresas que utilizam máquinas e implementos portáteis e tratores agrícolas adaptados ou não à atividade florestal;

- Mecanizado - empresas que atuam apenas a partir da utilização de tratores agrícolas e/ou florestais (Tabela 2).

Tabela 2. Empresas prestadoras de serviço amostradas por atividade e grau de mecanização.

Table 2. Rendering companies of service showed by activity and degree of mechanization.

\begin{tabular}{lcccc}
\hline Atividade & Manual & Semimecanizado & Mecanizado & Total \\
\hline Silvicultura & 0 & 10 & 0 & 10 \\
Colheita de Madeira & 8 & 14 & 4 & 26 \\
Transporte Florestal & 0 & 0 & 10 & 10 \\
Total & 8 & 24 & 14 & 46 \\
\hline
\end{tabular}

\section{Método}

A metodologia utilizada neste trabalho constituiu-se da aplicação de um questionário junto às empresas prestadoras de serviço florestal. Com a intenção de conhecer as empresas, bem como seus dirigentes, aplicou-se previamente um questionário a partir de entrevistas individuais com cada um dos dirigentes das empresas. básicos:

Inicialmente, as empresas prestadoras de serviço foram cadastradas a partir dos seguintes dados

- razão social;

- definição da atividade desenvolvida;

- identificação do sistema de produção;

- especificação da área de trabalho;

- definição da produção padrão mensal da prestadora de serviço.

Em seguida foram coletadas informações com o objetivo de conhecer o processo produtivo, o tipo e a forma de contratação, a atividade desenvolvida, as máquinas, implementos e funcionários envolvidos na produção e na administração.

O questionário também teve como meta analisar a percepção dos dirigentes quanto aos aspectos econômicos envolvidos na administração das empresas prestadoras de serviço florestal. Procurou-se identificar o conhecimento dos dirigentes quanto a alguns parâmetros econômicos, tais como o valor dos encargos e benefícios sociais incidentes sobre a folha de pagamento, o valor do capital investido na empresa, a participação do maior custo da empresa na receita bruta mensal e o percentual de impostos pagos sobre a receita bruta mensal. Após a elaboração do questionário, ele foi testado em quatro empresas prestadoras de serviço florestal e definido a partir desses testes.

\section{RESULTADOS E DISCUSSÃO}

\section{Caracterização da forma de atuação}

Capital em máquinas e implementos

A caracterização das empresas prestadoras de serviço de acordo com o valor do capital em máquinas e implementos diretos e indiretos está apresentada na figura 2. Verifica-se grande diversidade de valores, que demonstra uma heterogeneidade de sistemas operacionais. De modo geral, os investimentos em capital na produção equivalem a $85 \%$ do valor do capital total.

As empresas prestadoras de serviço que possuem os menores valores de capital em máquinas e implementos (empresas de um a seis) possuem apenas máquinas e implementos indiretos. Já as três 
empresas prestadoras de serviço que apresentam os maiores valores de capital em máquinas e implementos diretos e indiretos (empresas 44, 45 e 46) são de grande porte e operam a partir de sistemas mecanizados de colheita de madeira.

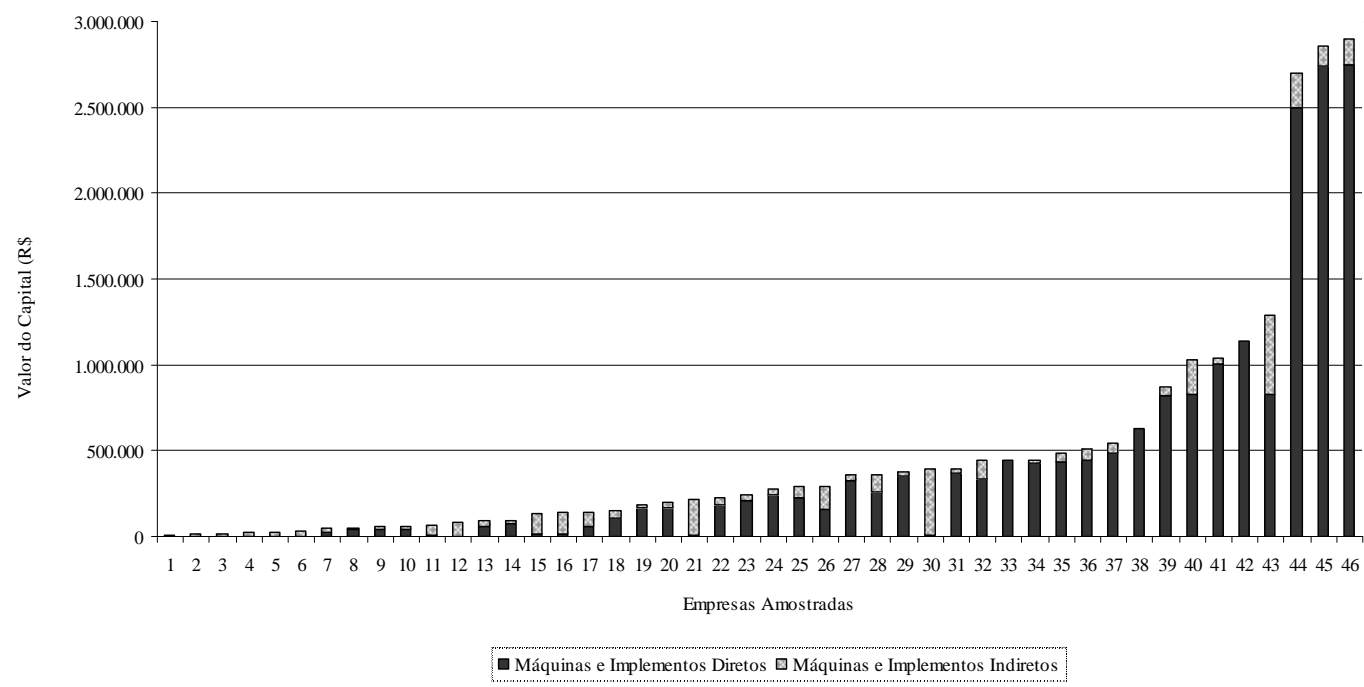

Figura 2. Capital em máquinas e implementos diretos e indiretos.

Figure 2. Capital in machines and implement direct and indirect.

As empresas que apresentam capitais preponderantemente em máquinas e implementos indiretos (empresas 11, 12, 15, 16, 21 e 30), atuam na colheita de madeira manual ou na silvicultura. As máquinas e equipamentos, de modo geral, são constituídos de ônibus e caminhões para transporte de pessoal. As empresas que possuem capital investido somente em máquinas e equipamentos diretos (empresas 33, 38 e 42) são empresas de transporte florestal.

Turnos de trabalho

Oitenta e sete por cento das empresas prestadoras de serviço pesquisadas operam em um único turno, $11 \%$ em dois turnos e apenas $2 \%$ em três turnos de trabalho. Das cinco empresas que operam em dois turnos, três são de colheita de madeira mecanizada e duas são de transporte florestal.

As empresas que operam em um único turno são constituídas por microempresas e empresas de pequeno porte que, devido às suas atividades e ao grau de mecanização (manual ou semimecanizado), não conseguem trabalhar em mais de um turno.

Contratantes e tipo de contrato

A tabela 3 mostra que as empresas que mais contratam as prestadoras de serviço da amostra são as empresas de papel e celulose, seguidas das empresas de energia e serrarias. Os investidores/silvicultores e os fabricantes de painéis também aparecem na amostragem, porém com menor participação.

Nota-se que $70 \%$ das empresas trabalham a partir de contratos com prazos anuais ou de mais de um ano. As empresas contratantes do ramo de papel e celulose proporcionam uma relativa segurança de continuidade da prestação de serviços. Quinze por cento das empresas pesquisadas trabalham sem contrato formal e têm sua atuação em serrarias e em empresas que utilizam reflorestamento para produzir energia. Apesar de haver poucas empresas prestadoras de serviço que trabalham para investidores/silvicultores, elas trabalham com contratos formais de um ano ou mais.

$\mathrm{Na}$ análise por tipo de atividade, percebe-se que as empresas de silvicultura que operam nas empresas de papel e celulose e serraria o fazem por meio de contratos formais de um ou mais anos. Já a 
atuação das empresas prestadoras de serviço de silvicultura em empresas que utilizam reflorestamento para produzir energia ocorre de modo informal. A maioria das empresas de colheita de madeira atua por meio de contratos formais. De modo geral, as empresas de transporte florestal não trabalham a partir de contratos, ou trabalham com contratos pontuais, o que demonstra a ocorrência de mobilidade de empresas prestadoras de serviço nessa atividade.

Tabela 3. Empresas prestadoras de serviço por contratante, por forma de contrato e por tipo de atividade.

Table 3. Rendering companies of service for contractor, contract form and type of activity.

\begin{tabular}{|c|c|c|c|c|c|}
\hline $\begin{array}{l}\text { Tipo de } \\
\text { contratante }\end{array}$ & Forma de contrato & $\begin{array}{l}\text { Empresas de } \\
\text { silvicultura }\end{array}$ & $\begin{array}{c}\text { Empresas de } \\
\text { colheita de } \\
\text { madeira }\end{array}$ & $\begin{array}{c}\text { Empresas de } \\
\text { transporte } \\
\text { florestal }\end{array}$ & $\begin{array}{c}\text { Total de } \\
\text { empresas }\end{array}$ \\
\hline \multirow[t]{5}{*}{ Papel e Celulose } & Sem contrato & 0 & 0 & 0 & 0 \\
\hline & Pontual & 0 & 1 & 1 & 2 \\
\hline & De 1 ano & 2 & 8 & 0 & 10 \\
\hline & De mais de 1 ano & 2 & 4 & 2 & 8 \\
\hline & Total & 4 & 13 & 3 & 20 \\
\hline \multirow[t]{5}{*}{ Painéis } & Sem contrato & 0 & 0 & 0 & 0 \\
\hline & Pontual & 0 & 0 & 0 & 0 \\
\hline & De 1 ano & 0 & 2 & 1 & 3 \\
\hline & De mais de 1 ano & 0 & 0 & 0 & 0 \\
\hline & Total & 0 & 2 & 1 & 3 \\
\hline \multirow[t]{5}{*}{ Serraria } & Sem contrato & 0 & 0 & 3 & 3 \\
\hline & Pontual & 1 & 1 & 1 & 3 \\
\hline & De 1 ano & 1 & 0 & 0 & 1 \\
\hline & De mais de 1 ano & 1 & 1 & 0 & 2 \\
\hline & Total & 3 & 2 & 4 & 9 \\
\hline \multirow[t]{5}{*}{ Energia } & Sem contrato & 2 & 0 & 2 & 4 \\
\hline & Pontual & 1 & 1 & 0 & 2 \\
\hline & De 1 ano & 0 & 2 & 0 & 2 \\
\hline & De mais de 1 ano & 0 & 2 & 0 & 2 \\
\hline & Total & 3 & 5 & 2 & 10 \\
\hline \multirow[t]{5}{*}{ Investidores } & Sem contrato & 0 & 0 & 0 & 0 \\
\hline & Pontual & 0 & 0 & 0 & 0 \\
\hline & De 1 ano & 0 & 3 & 0 & 3 \\
\hline & De mais de 1 ano & 0 & 1 & 0 & 1 \\
\hline & Total & 0 & 4 & 0 & 4 \\
\hline \multicolumn{2}{|c|}{ Total de empresas por atividade } & 10 & 26 & 10 & 46 \\
\hline
\end{tabular}

Atendimento aos contratos

Observa-se na tabela 4 que $43 \%$ das empresas prestadoras de serviço julgam-se cumpridoras da produção contratada e/ou demandada. Cinco empresas afirmaram não atender à produção contratada e alegaram problemas de ordem técnico-operacional.

Em termos gerais, pode-se avaliar que há no setor seriedade por parte das empresas prestadoras de serviço no que tange à execução das produções contratadas e/ou demandadas, pois a maioria dos dirigentes acredita cumprir com suas obrigações.

Número total de funcionários

As empresas prestadoras de serviço pesquisadas possuem, em média, 20 funcionários, dos quais 18 são da produção e dois são da administração. 
Tabela 4. Empresas prestadoras de serviço de acordo com o atendimento ao contrato ou à demanda, por forma de contrato e tipo de atividade.

Table 4. Rendering companies of service in agreement with the attendance to the contract or the demand, for form of contract and type of activity.

\begin{tabular}{lccccc}
\hline $\begin{array}{l}\text { Atendimento ao } \\
\text { contrato }\end{array}$ & Forma de contrato & $\begin{array}{c}\text { Empresas de } \\
\text { silvicultura }\end{array}$ & $\begin{array}{c}\text { Empresas de } \\
\text { colheita de } \\
\text { madeira }\end{array}$ & $\begin{array}{c}\text { Empresas de } \\
\text { transporte } \\
\text { florestal }\end{array}$ & $\begin{array}{c}\text { Número total } \\
\text { de empresas }\end{array}$ \\
\hline Atendem ao & Sem contrato & 2 & 0 & 1 & 3 \\
contrato & Pontual & 2 & 0 & 0 & 2 \\
& De 1 ano & 3 & 4 & 0 & 7 \\
& De mais de 1 ano & 3 & 3 & 2 & 8 \\
& Total & 10 & 7 & 3 & 20 \\
\hline Atende com & Sem contrato & 0 & 0 & 3 & 3 \\
variação de +/- & Pontual & 0 & 0 & 1 & 1 \\
$10 \%$ & De 1 ano & 0 & 9 & 0 & 9 \\
& De mais de 1 ano & 0 & 5 & 0 & 5 \\
& Total & 0 & 14 & 4 & 18 \\
\hline Atende com & Sem Contrato & 0 & 0 & 1 & 1 \\
variação de $+/-$ & Pontual & 0 & 1 & 0 & 1 \\
$20 \%$ & de 1 ano & 0 & 1 & 0 & 1 \\
& de mais de 1 ano & 0 & 0 & 0 & 0 \\
& Total & 0 & 2 & 1 & 3 \\
\hline Não atende à & Sem Contrato & 0 & 0 & 0 & 0 \\
produção & Pontual & 0 & 2 & 1 & 3 \\
contratada & De 1 ano & 0 & 1 & 1 & 2 \\
& De mais de 1 ano & 0 & 0 & 0 & 0 \\
& Total & 0 & 3 & 2 & 5 \\
\hline Total geral & & 10 & 26 & 10 & 46 \\
\hline
\end{tabular}

Tabela 5. Total de funcionários por empresa prestadora de serviço florestal.

Table 5. Total of employees for rendering company of forest service.

\begin{tabular}{lccc}
\hline & Número mínimo & Média & Número máximo \\
\hline Produção & 2 & 18 & 63 \\
Administração & 0 & 2 & 9 \\
\hline Total & 2 & 20 & 69 \\
\hline
\end{tabular}

Número de funcionários de produção e administração

$\mathrm{Na}$ tabela 6 constata-se que as empresas de silvicultura são as que possuem, em média, o maior número de funcionários (28), pois elas necessitam utilizar intensa quantidade de mão de obra. As empresas de colheita de madeira possuem, em média, 22 funcionários, pois grande parte delas atua com sistemas manuais ou semimecanizados. As empresas que atuam nessa atividade com sistemas mecanizados utilizam pequena quantidade de mão de obra. As empresas de transporte florestal possuem o menor número de funcionários.

Tabela 6. Funcionários de produção e administração por atividade.

Table 6. Production employees and administration for activity.

\begin{tabular}{lcccccc}
\hline & \multicolumn{2}{c}{ Silvicultura } & \multicolumn{2}{c}{ Colheita de madeira } & \multicolumn{2}{c}{ Transporte florestal } \\
\cline { 2 - 7 } & $\mathrm{N}^{\mathbf{o}}$ & $\%$ & $\mathrm{~N}^{\mathbf{0}}$ & $\%$ & $\mathrm{~N}^{\mathbf{o}}$ & $\%$ \\
\hline Produção & 25 & 89 & 20 & 91 & 7 & 87 \\
Administração & 3 & 11 & 2 & 9 & 1 & 13 \\
\hline Total & 28 & 100 & 22 & 100 & 8 & 100 \\
\hline
\end{tabular}


Destaca-se que o número relativo de funcionários de administração em relação ao número total de funcionários é semelhante nos diferentes tipos de atividades, correspondendo a um valor aproximado de $10 \%$.

Escolaridade dos funcionários de produção e administração

Observa-se, na tabela 7, que a maioria dos funcionários de produção tem escolaridade inferior ao fundamental completo. A escolaridade dos funcionários de produção nas empresas de transporte florestal é mais elevada que nas empresas de silvicultura e colheita de madeira.

Tabela 7. Escolaridade dos funcionários de produção e administração por atividade.

Table 7. Level of study of the production employees and administration for activity.

\begin{tabular}{lcccccc}
\hline \multirow{2}{*}{ Escolaridade } & \multicolumn{2}{c}{ Silvicultura } & \multicolumn{2}{c}{ Colheita de madeira } & \multicolumn{2}{c}{ Transporte florestal } \\
\cline { 2 - 7 } & $\begin{array}{c}\text { Produção } \\
(\boldsymbol{\%})\end{array}$ & $\begin{array}{c}\text { Adm. } \\
(\boldsymbol{\%})\end{array}$ & $\begin{array}{c}\text { Produção } \\
(\boldsymbol{\%})\end{array}$ & $\begin{array}{c}\text { Adm. } \\
(\boldsymbol{\%})\end{array}$ & $\begin{array}{c}\text { Produção } \\
(\boldsymbol{\%})\end{array}$ & $\begin{array}{c}\text { Adm. } \\
(\boldsymbol{\%})\end{array}$ \\
\hline Analfabeto & 12 & 3 & 15 & 0 & 0 & 0 \\
Fundamental incompleto & 68 & 23 & 60 & 26 & 57 & 10 \\
Fundamental completo & 20 & 20 & 15 & 29 & 29 & 0 \\
Médio incompleto & 0 & 17 & 5 & 7 & 14 & 30 \\
Médio completo & 0 & 17 & 5 & 17 & 0 & 30 \\
Superior incompleto & 0 & 7 & 0 & 7 & 0 & 10 \\
Superior completo & 0 & 7 & 0 & 12 & 0 & 20 \\
Pós-graduação incompleta & 0 & 3 & 0 & 0 & 0 & 0 \\
Pós-graduação completa & 0 & 3 & 0 & 2 & 0 & 0 \\
\hline Total & 100 & 100 & 100 & 100 & 100 & 100 \\
\hline
\end{tabular}

Observa-se que nenhum funcionário de produção possui escolaridade superior ao ensino médio completo, fato que demonstra que, apesar da tecnologia existente em algumas máquinas e implementos, as empresas prestadoras de serviço não contratam funcionários com níveis educacionais acima do médio completo.

As empresas prestadoras de serviço são administradas por pessoas pertencentes aos mais diversos níveis de escolaridade. Há baixo número de funcionários da administração que possui nível superior completo, o que revela que a maior parte dos funcionários da administração não possui escolaridade suficiente para entender os preceitos econômicos necessários à administração de empresas.

Salários da produção e administração

Na tabela 8 constata-se que os funcionários de produção da silvicultura possuem salários mais baixos que os de colheita de madeira e transporte florestal. Isso ocorre devido à alta concentração de operações manuais relacionadas com o plantio e manutenção de reflorestamentos. As empresas de colheita de madeira e de transporte florestal possuem distribuição dos funcionários de produção por faixa salarial de forma similar. Em nenhuma atividade de produção existem funcionários que recebem salários acima de seis salários mínimos.

Tabela 8. Funcionários de produção e administração por faixa salarial e por atividade.

Table 8. Production employees and administration for wage band and activity.

\begin{tabular}{lcccccc}
\hline \multirow{2}{*}{ Salários } & \multicolumn{2}{c}{ Silvicultura } & \multicolumn{2}{c}{ Colheita de madeira } & \multicolumn{2}{c}{ Transporte florestal } \\
\cline { 2 - 7 } & $\begin{array}{c}\text { Produção } \\
(\boldsymbol{\%})\end{array}$ & $\begin{array}{c}\mathbf{A d m} \\
(\mathbf{\%})\end{array}$ & $\begin{array}{c}\text { Produção } \\
(\boldsymbol{\%})\end{array}$ & $\begin{array}{c}\text { Adm. } \\
(\boldsymbol{\%})\end{array}$ & $\begin{array}{c}\text { Produção } \\
(\boldsymbol{\%})\end{array}$ & $\begin{array}{c}\text { Adm. } \\
(\boldsymbol{\%})\end{array}$ \\
\hline Até 2 salários mínimos/mês & 83 & 3 & 40 & 5 & 44 & 0 \\
De 2 a 4 salários mínimos/mês & 16 & 23 & 49 & 23 & 51 & 10 \\
De 4 a 6 salários mínimos/mês & 1 & 20 & 11 & 27 & 5 & 10 \\
Acima de 6 salários mínimos/mês & 0 & 54 & 0 & 45 & 0 & 80 \\
\hline Total & 100 & 100 & 100 & 100 & 100 & 100 \\
\hline
\end{tabular}


Pela análise dos salários dos funcionários da administração, pode-se verificar que as empresas de silvicultura e colheita de madeira possuem semelhante distribuição salarial. A maioria dos funcionários de administração pertence às classes salariais superiores, por possuírem maiores níveis de escolaridade.

\section{Percepção dos dirigentes das empresas prestadoras de serviço florestal}

Necessidade de treinamento

$\mathrm{Na}$ tabela 9 nota-se que a maioria dos dirigentes entende que seus funcionários de produção não necessitam, ou necessitam de, no máximo, quatro horas de treinamento por mês.

Tabela 9. Necessidade de treinamento dos funcionários de produção e administração por tipo de atividade.

Table 9. Training necessity of the production employees and administration for type of activity.

\begin{tabular}{lcccccc}
\hline & \multicolumn{2}{c}{ Silvicultura } & \multicolumn{2}{c}{ Colheita de madeira } & \multicolumn{2}{c}{ Transporte florestal } \\
\cline { 2 - 7 } & $\begin{array}{c}\text { Produção } \\
(\mathbf{\%})\end{array}$ & $\begin{array}{c}\text { Adm. } \\
(\mathbf{\%})\end{array}$ & $\begin{array}{c}\text { Produção } \\
(\mathbf{\%})\end{array}$ & $\begin{array}{c}\text { Adm. } \\
(\mathbf{\%})\end{array}$ & $\begin{array}{c}\text { Produção } \\
(\boldsymbol{\%})\end{array}$ & $\begin{array}{c}\text { Adm. } \\
(\boldsymbol{\%})\end{array}$ \\
\hline Nenhuma hora de treinamento por mês & 37 & 70 & 35 & 42 & 57 & 90 \\
Até 4 horas de treinamento por mês & 63 & 17 & 31 & 3 & 33 & 0 \\
De 4 a 10 horas de treinamento por mês & 0 & 13 & 34 & 53 & 10 & 0 \\
$\begin{array}{l}\text { Acima de 10 horas de treinamento por } \\
\text { mês }\end{array}$ & 0 & 0 & 0 & 2 & 0 & 10 \\
\hline Total & 100 & 100 & 100 & 100 & 100 & 100 \\
\hline
\end{tabular}

Em relação aos funcionários da administração, na atividade de silvicultura e transporte florestal, a percepção dos dirigentes é de que os funcionários não necessitam de treinamento. Essa constatação é preocupante, pois a falta de capacitação pode ocasionar dificuldades na gestão das empresas.

Principais problemas existentes

Apesar de nos últimos anos ter havido um aumento do grau de mecanização no setor florestal, nas amostras analisadas o acidente de trabalho ainda é percebido pelos dirigentes como o maior problema. Nas atividades de colheita de madeira, esse problema se destaca, alcançando um percentual de $61 \%$ (Tabela 10).

Tabela 10. Percepção dos dirigentes quanto aos maiores problemas por atividade.

Table 10. Perception of the controllers as much as the biggest problems for activity.

\begin{tabular}{lccc}
\hline Tipos de problema & Silvicultura (\%) & $\begin{array}{c}\text { Colheita de } \\
\text { madeira }(\%)\end{array}$ & $\begin{array}{c}\text { Transporte } \\
\text { florestal }(\%)\end{array}$ \\
\hline Acidente de trabalho & 50 & 61 & 20 \\
Fim de contrato & 20 & 23 & 10 \\
Problemas jurídicos/trabalhistas & 20 & 12 & 20 \\
Acidente de trânsito & 0 & 0 & 30 \\
Roubo de máquinas e implementos & 0 & 0 & 20 \\
Mudanças tributárias & 10 & 0 & 0 \\
Não atingir metas & 0 & 4 & 0 \\
\hline Total & 100 & 100 & 100 \\
\hline
\end{tabular}

Os dirigentes de todas as atividades citaram também os problemas relacionados à possibilidade de fim de contrato, problemas jurídico/trabalhistas e mudanças tributárias como importantes. De modo geral, os dirigentes têm grandes preocupações relacionadas aos problemas advindos da operação do serviço, para, em seguida, preocuparem-se com os problemas relacionados às questões de ordem econômico/gerenciais.

Vantagens e desvantagens da atividade

As principais vantagens apontadas pelos dirigentes na execução de suas atividades são as condições topográficas, a rede viária e os turnos de trabalho (Tabela 11). 
Tabela 11. Percepção dos dirigentes quanto às principais vantagens e desvantagens da atividade.

Table 11. Perception of the controllers as much as the main advantages and disadvantages of the activity.

\begin{tabular}{lcc}
\hline Principais vantagens e/ou desvantagens & Vantagem (\%) & Desvantagem (\%) \\
\hline Turnos de trabalho & 14 & 2 \\
Necessidade de planejamento da contratante & 2 & 3 \\
Necessidade de treinamento & 0 & 5 \\
Investimento alto em relação à receita bruta mensal & 5 & 10 \\
Investimento baixo em relação à receita bruta mensal & 16 & 1 \\
Custo alto em relação à receita bruta mensal & 2 & 14 \\
Custo baixo em relação à receita bruta mensal & 11 & 1 \\
Necessidade de apoio logístico & 1 & 7 \\
Rede viária & 18 & 5 \\
Condições topográficas & 18 & 6 \\
Número de funcionários envolvidos & 7 & 11 \\
Diferenciação entre talhões & 0 & 5 \\
Fiscalização de campo & 4 & 3 \\
Falta de integração entre atividades & 0 & 6 \\
Problemas ambientais & 0 & 9 \\
Ausência inesperada de funcionários & 2 & 12 \\
\hline Total & 100 & \\
\hline
\end{tabular}

$\mathrm{Na}$ atividade de silvicultura, os dirigentes assinalaram como principais vantagens a rede viária e as condições topográficas e, em termos econômicos, o turno de trabalho, o investimento e o custo baixo em relação à receita bruta mensal. Observa-se que nessa atividade os dirigentes possuem uma preocupação com as questões técnicas, no que se refere às definições de produção e tipo de terreno a ser trabalhado, que, por sua vez, influenciam os resultados econômicos das empresas.

Os dirigentes das empresas de colheita de madeira apontaram como vantagem a rede viária e as condições topográficas, que também são fatores com forte influência nos resultados econômicos nessa atividade. Pode-se afirmar ainda que, à medida que as empresas são mais mecanizadas, mais preocupados mostraram-se os dirigentes com as questões econômicas, pois as empresas pequenas apontaram como vantagem o baixo custo e o baixo investimento, enquanto os dirigentes das grandes empresas indicaram esses mesmos itens como desvantagem.

Os dirigentes que atuam nas empresas de transporte florestal assinalaram como vantagem o turno de trabalho, o baixo número de funcionários envolvidos e os custos baixos em relação à receita bruta mensal. Como desvantagem, a necessidade de apoio logístico e o investimento alto em relação à receita bruta mensal. Aqui também predomina a preocupação com as questões técnicas em detrimento das econômicas.

Os dirigentes que afirmaram ser uma vantagem o investimento baixo em relação à receita bruta mensal atuam nas empresas de colheita de madeira manual e semimecanizada, assim como na silvicultura semimecanizada, pois essas empresas necessitam de pouco investimento em capital.

\section{Definição da forma de trabalho}

O percentual de dirigentes que define a sua forma de trabalho a partir das exigências das empresas contratantes é alto em todas as atividades (Tabela 12), fato que decorre da existência de uma forte relação de dependência entre a tomadora e a prestadora de serviço.

Alguns dirigentes definem a sua forma de trabalho a partir da análise das empresas que executam atividades similares e a partir da oferta de máquinas e implementos por parte dos vendedores. Nota-se que as ferramentas econômicas que auxiliam na análise do processo produtivo, tais como análise de custo e de rentabilidade e a consequente melhoria deste, não foram apontadas como importantes pelos dirigentes na definição da forma de trabalho.

Poucas empresas prestadoras de serviço definem a sua forma de trabalho a partir da análise econômica (análise de custos e de rentabilidade) e técnico-econômica (análise operacional, de custos e de 
rentabilidade), o que demonstra que existe na amostra de empresas prestadoras de serviço florestal baixa capacidade de análise e melhoria das condições econômicas dessas empresas.

Tabela 12. Percepção dos dirigentes quanto à prioridade na definição da forma de trabalho.

Table 12. Perception of the controllers as much as the priority in the definition of the work form.

\begin{tabular}{lccc}
\hline Prioridade na definição da forma de trabalho & Silvicultura (\%) & $\begin{array}{c}\text { Colheita de } \\
\text { madeira (\%) }\end{array}$ & $\begin{array}{c}\text { Transporte florestal } \\
(\%)\end{array}$ \\
\hline Exigência da empresa contratante & 60 & 46 & 60 \\
Análise econômica & 10 & 4 & 0 \\
Análise técnica & 0 & 0 & 0 \\
Análise técnico-econômica & 10 & 15 & 10 \\
Análise dos concorrentes & 0 & 27 & 20 \\
Oferta de vendedores de máquinas e implementos & 20 & 8 & 10 \\
\hline Total & 100 & 100 & 100 \\
\hline
\end{tabular}

Aquisição de máquinas e implementos

Quando analisados os fatores de influência acima explicitados, porém agora analisando-os com relação à influência na aquisição de máquinas e implementos, observou-se que os dirigentes levam em consideração a oferta de máquinas e implementos por parte dos vendedores, bem como a análise das empresas prestadoras de serviço que executam a mesma atividade. Ressalte-se que este último fator tem uma influência de $42 \%$ na compra de máquinas e implementos na atividade de colheita de madeira (Tabela 13)

Tabela 13. Percepção dos dirigentes quanto à definição de prioridade na aquisição de máquinas e implementos.

Table 13. Perception of the controllers as much as the definition of priority in the acquisition of machines and implements.

\begin{tabular}{lccc}
\hline Parâmetros & $\begin{array}{c}\text { Silvicultura } \\
(\boldsymbol{\%})\end{array}$ & $\begin{array}{c}\text { Colheita de } \\
\text { madeira (\%) }\end{array}$ & $\begin{array}{c}\text { Transporte } \\
\text { florestal }(\%)\end{array}$ \\
\hline Exigência da empresa contratante & 20 & 23 & 20 \\
Análise econômica & 10 & 0 & 0 \\
Análise técnica & 0 & 0 & 0 \\
Análise técnico-econômica & 10 & 12 & 20 \\
Análise dos concorrentes & 30 & 42 & 30 \\
Oferta de vendedores de máquinas e implementos & 30 & 23 & 30 \\
\hline Total & 100 & 100 & 100 \\
\hline
\end{tabular}

A exigência da empresa contratante continua a influenciar a administração das empresas prestadoras de serviço, dessa vez no processo de aquisição de máquinas e implementos. Verificou-se, novamente, pequena importância dos fatores técnicos e/ou econômicos na aquisição de máquinas e implementos, o que pode ser explicado pela dificuldade que a maioria dos dirigentes possui em conhecer tais fatores.

Análise de custos e rentabilidade econômica

$\mathrm{Na}$ tabela 14 nota-se que a maioria das empresas não faz análise de custo. Nas análises anteriores, que se referiam à definição da forma de trabalho e à aquisição de máquinas e implementos, o percentual de empresas que asseguraram basear suas análises em parâmetros econômicos foi bem menor, o que evidencia que, apesar de alguns dirigentes afirmarem que calculam seus custos, não os utilizam em suas funções gerenciais.

Em torno de $10 \%$ das empresas prestadoras de serviço analisadas indicaram possuir um sistema de análise de rentabilidade de suas atividades. Ressalte-se aqui a ocorrência de um grande problema junto às empresas pesquisadas, pois a maioria não analisa a sua rentabilidade e, dessa forma, fica sujeita aos preços do mercado sem saber se eles são suficientes para proporcionar uma boa condição econômica às suas empresas. 
Tabela 14. Percepção dos dirigentes quanto à existência de análise de custos e rentabilidade.

Table 14. Perception of the controllers as much as the existence of analysis of costs and yield.

\begin{tabular}{|c|c|c|c|c|}
\hline & & Silvicultura (\%) & Colheita de madeira (\%) & Transporte florestal (\%) \\
\hline \multirow{2}{*}{ Faz análise de custo } & SIM & 30 & 38 & 20 \\
\hline & NÃO & 70 & 62 & 80 \\
\hline Total & & 100 & 100 & 100 \\
\hline \multirow{2}{*}{ Faz análise de rentabilidade } & SIM & 10 & 12 & 10 \\
\hline & NÃO & 90 & 88 & 90 \\
\hline Total & & 100 & 100 & 100 \\
\hline
\end{tabular}

Maiores custos das atividades

Os dirigentes das empresas prestadoras de serviço afirmaram que o item mais oneroso é o salário, e a percepção deles é que o mesmo corresponde de 40 a $48 \%$ do custo total de suas empresas (Tabela 15). Em seguida, foram definidos como maior custo os relacionados às máquinas e implementos, mais precisamente os custos de reparos e manutenção e combustíveis. Nota-se que há grande preocupação com os custos operacionais, e destaca-se que nenhum dirigente se referiu aos custos governamentais (impostos), aos custos de depreciação e aos custos administrativos.

Tabela 15. Percepção dos dirigentes quanto ao maior custo da atividade.

Table 15. Perception of the controllers as much as the biggest cost of the activity.

\begin{tabular}{|c|c|c|c|c|c|c|c|}
\hline \multirow[b]{2}{*}{$\begin{array}{l}\text { Especificação do } \\
\text { maior custo }\end{array}$} & \multicolumn{2}{|c|}{ Silvicultura } & \multicolumn{2}{|c|}{ Colheita de madeira } & \multicolumn{2}{|c|}{ Transporte florestal } & \multirow[b]{2}{*}{$\begin{array}{c}\text { Número } \\
\text { total de } \\
\text { empresas }\end{array}$} \\
\hline & $\begin{array}{l}\text { Número de } \\
\text { empresas }\end{array}$ & $\begin{array}{c}\text { Participação } \\
\text { do maior } \\
\text { custo no } \\
\text { custo total } \\
(\%) \\
\end{array}$ & $\begin{array}{l}\text { Número } \\
\text { de } \\
\text { empresas }\end{array}$ & $\begin{array}{l}\text { Participação } \\
\text { do maior } \\
\text { custo no custo } \\
\text { total }(\%)\end{array}$ & $\begin{array}{l}\text { Número } \\
\text { de } \\
\text { empresa } \\
\mathbf{s}\end{array}$ & $\begin{array}{c}\text { Participação } \\
\text { do maior } \\
\text { custo no } \\
\text { custo total } \\
(\%) \\
\end{array}$ & \\
\hline Salário & 9 & 48 & 21 & 46 & 2 & 40 & 32 \\
\hline $\begin{array}{l}\text { Reparos e } \\
\text { manutenção }\end{array}$ & 1 & 25 & 4 & 39 & 4 & 28 & 9 \\
\hline Combustível & 0 & 0 & 1 & 30 & 1 & 30 & 2 \\
\hline Investimentos & 0 & 0 & 0 & 0 & 3 & 22 & 3 \\
\hline Total & 10 & - & 26 & - & 10 & - & 46 \\
\hline
\end{tabular}

Das dez empresas de silvicultura, nove asseguraram ser o salário o seu maior custo. As empresas de colheita de madeira afirmaram ser o salário o maior custo, fato que ocorre devido à maioria das empresas operarem com sistemas manuais ou semimecanizados.

Encargos e benefícios sociais

Os dirigentes definiram números diferentes dos reais em termos de encargos sociais. Theiss e Krieck (2005) afirmam que o percentual de encargos sociais está em torno de $85 \%$.

Tabela 16. Percepção dos dirigentes quanto aos valores dos encargos e benefícios sociais. Table 16. Perception of the controllers as much as the responsibilities values and social benefits.

\begin{tabular}{lcccc}
\hline Salário & Especificação & $\begin{array}{c}\text { Silvicultura } \\
(\boldsymbol{\%})\end{array}$ & $\begin{array}{c}\text { Colheita de } \\
\text { madeira (\%) }\end{array}$ & $\begin{array}{c}\text { Transporte } \\
\text { florestal (\%) }\end{array}$ \\
\hline Produção & Encargos sociais & 41 & 46 & 42 \\
\multirow{2}{*}{ Administração } & Benefícios sociais & 7 & 5 & 7 \\
& Encargos sociais & 33 & 45 & 32 \\
& Benefícios sociais & 6 & 5 & 4 \\
\hline
\end{tabular}

Os valores médios definidos pelos dirigentes como sendo os percentuais de benefícios sociais ficaram em torno de 5\%, o que pode ser considerado normal para as empresas do setor. Destaca-se que, na maioria dos casos, foi necessário explicar aos dirigentes a diferença conceitual existente entre encargos e benefícios sociais. 
Despesas governamentais

Os dirigentes das empresas prestadoras de serviço definiram como sendo em torno de $16 \%$ o valor dos impostos incidentes sobre a receita bruta total. Os dirigentes têm boa noção do percentual de impostos pagos sobre a receita bruta, no entanto não sabem quais são esses impostos e seus percentuais (Tabela 17).

Tabela 17. Percepção dos dirigentes quanto às despesas governamentais.

Table 17. Perception of the controllers as much as the governmental expenditures.

\begin{tabular}{lccc}
\hline Percepção dos dirigentes & $\begin{array}{c}\text { Silvicultura } \\
(\%)\end{array}$ & $\begin{array}{c}\text { Colheita de } \\
\text { madeira (\%) }\end{array}$ & $\begin{array}{c}\text { Transporte } \\
\text { florestal (\%) }\end{array}$ \\
\hline $\begin{array}{l}\text { Quanto ao percentual de impostos pagos sobre a } \\
\text { receita bruta }\end{array}$ & 15 & 15 & 17 \\
$\begin{array}{l}\text { Quanto ao conhecimento das alíquotas de impostos } \\
\text { pagos sobre a receita bruta }\end{array}$ & 0 & 15 & 20 \\
\hline
\end{tabular}

\section{CONCLUSÕES}

- A partir dos resultados apresentados neste trabalho, pode-se afirmar que nas duas regiões estudadas atuam empresas prestadoras de serviço florestal que possuem distintos tamanhos de produção e estruturas administrativas, com consequentes diferentes sistemas operacionais, desde os mais simples, que se utilizam de sistemas manuais, até empresas que utilizam máquinas e equipamentos de última geração. Na região do Vale do Itajaí/SC, as empresas são menores, utilizam menos tecnologia e os dirigentes têm escolaridade baixa. No Planalto Serrano/SC, as empresas são maiores, utilizam máquinas e implementos tecnologicamente mais evoluídos e os dirigentes possuem escolaridade alta.

- Conclui-se ainda que os dirigentes das empresas prestadoras de serviço, em ambas as regiões analisadas, priorizam a análise técnica em detrimento das questões econômicas. Encontraram-se dirigentes que, de modo geral, conhecem muito bem os aspectos técnicos e operacionais de sua atividade, no entanto não conhecem a economia de suas empresas. Precisam, portanto, de uma maior capacidade administrativa no que se refere ao conhecimento de seus custos, receitas e lucros.

- Muitos dirigentes definem os principais parâmetros econômicos de forma errônea e longe da realidade nacional, de maneira especial quando se analisam as questões trabalhistas, previdenciárias e fiscais. Esse talvez seja o grande problema das empresas prestadoras de serviço analisadas neste estudo.

- Os dirigentes das empresas prestadoras de serviço florestal que atuam na região do Vale do Itajaí, de maneira especial as microempresas ou empresas de pequeno porte, não possuem conhecimento técnico e econômico compatível com a necessária capacidade empresarial para atuar no mercado. Esse fato não foi percebido junto aos dirigentes das empresas prestadoras de serviço localizadas no Planalto Serrano, onde a profissionalização é, notadamente, superior e o grau de mecanização, de modo geral, é elevado.

- Os dirigentes das empresas prestadoras de serviço florestal da amostra analisada, de modo geral, necessitam se aperfeiçoar para administrar de forma mais profissional suas empresas.

- Finalizando, conclui-se que o modelo desenvolvido no presente estudo permitiu caracterizar e distinguir as empresas prestadoras de serviço florestal, pois a definição da forma de atuação utilizada e a análise da percepção dos seus dirigentes em termos dos parâmetros econômicos comprovaram que as empresas que atuam em distintas regiões do estado de Santa Catarina são diferentes sob diversos aspectos, representando, desse modo, um rico campo de pesquisa para outros trabalhos científicos.

\section{REFERÊNCIAS}

BINDA, J. A. Análise da terceirização na colheita florestal sob o ponto de vista do terceiro. In: SEMINÁRIO DE ATUALIZAÇÃO EM SISTEMAS DE COLHEITA DE MADEIRA E TRANSPORTE FLORESTAL, 12., 2002, Curitiba. Anais... Curitiba: UFPR; FUPEF, 2002. 
FERNANDES, O. R. Diretrizes estratégicas para a consolidação da terceirização no setor florestal brasileiro: Proposta - versão 3.0. In: SEMINÁRIO DE ATUALIZAÇÃO EM SISTEMAS DE COLHEITA DE MADEIRA E TRANSPORTE FLORESTAL, 12., 2002, Curitiba. Anais... Curitiba: UFPR; FUPEF, 2002.

FLORIANÓPOLIS. Governo do Estado de Santa Catarina. Mapa político de Santa Catarina. Disponível em: <http://www.sc.gov.br/conteudo/santacatarina/geografia/paginas/mapas.htm>. Acesso em: 05/07/2008.

LACOMBE, F. J. M.; HEILBORN, G. L. J. Administração: princípios e tendências. São Paulo: Saraiva, 2003. 542 p.

MALINOVSKI, J. R. A importância do setor florestal terceirizado. SEMINÁRIO DE ATUALIZAÇÃO SOBRE SISTEMAS DE COLHEITA DE MADEIRA E TRANSPORTE FLORESTAL, 13., 2004, Curitiba. Palestra de abertura. Curitiba: UFPR; FUPEF, 2004.

MALINOWSKI, J. Terceirização. In: SEMINÁRIO DE ATUALIZAÇÃO EM SISTEMAS DE COLHEITA DE MADEIRA E TRANSPORTE FLORESTAL, 13., 2004, Curitiba. Anais... Curitiba: UFPR; FUPEF, 2004.

SALAMUNI, R. Terceirização na RIPASA. In: SEMINÁRIO DE ATUALIZAÇÃO EM SISTEMAS DE COLHEITA DE MADEIRA E TRANSPORTE FLORESTAL, 13., 2004, Curitiba. Anais... Curitiba: UFPR; FUPEF, 2004.

SANT'ANNA JÚNIOR, M.; LAZARETTI, D. S. Controle de qualidade na terceirização. Terceirização. In: SEMINÁRIO DE ATUALIZAÇÃO EM SISTEMAS DE COLHEITA DE MADEIRA E TRANSPORTE FLORESTAL, 14., 2006, Curitiba. Anais... Curitiba: UFPR; FUPEF, 2006.

THEISS, J. R.; KRIECK, M. Custos e preços sugeridos de venda: serviços, comércio e indústria: enfoques essencialmente práticos. 2. ed. Blumenau: Odorizzi, 2005. 147 p. 